\title{
Analysis of the Responses of Science Teacher Candidates to Force Concept Inventory by Concentration Factor
}

\author{
Ebru Ezberci Cevik ${ }^{1, *}$, Mehmet Altan Kurnaz ${ }^{2}$ \\ ${ }^{1}$ Department of Science Education, Faculty of Education, Erciyes University, Turkey \\ ${ }^{2}$ Department of Science Education, Faculty of Education, Kastamonu University, Turkey
}

Copyright $(2019$ by authors, all rights reserved. Authors agree that this article remains permanently open access under the terms of the Creative Commons Attribution License 4.0 International License

\begin{abstract}
This study aims to obtain information about the modelling situations related to the topic by performing concentration analysis of teacher candidates' responses to Force Concept Inventory (FCI). The research was conducted using survey model, which is a quantitative research method. The study was carried out in the fall semester of the academic year 2015-2016 among 95 freshman teacher candidates enrolled in the Science Education Program of the Faculty of Education at a university in the Western Black Sea region. The data collection tool employed was FCI. In this context, concentration score, concentration factor and concentration deviation formulas were used. In light of the results obtained, it was determined that the responses of teacher candidates correspond to the null model, meaning that it is a result of a random reaction. It was suggested that this method of analysis could be used to develop more effective multiple-choice tests and comprehensively assess the learning situation of a class in depth.
\end{abstract}

Keywords Concentration Factor, Force, Force Concept Inventory

\section{Introduction}

At the undergraduate level, nearly all students in programmes related to science take introductory physics courses during their first year. They begin the introductory physics course with the accumulation of knowledge consisting of individual experiences and the acquisition of science, based on the physics courses taken in the previous years. In terms of content, introductory physics generally reflects the simplified and reduced form of physics subjects. The students of the introductory physics course are expected to generate solutions and make decisions based on fundamental knowledge of physics when faced with problems pertaining to society such as social and economic matters. Nevertheless, it is reported that some students experience difficulty, especially conceptual learning problems, while learning physics $[1,2,3,4]$. To find the unknown values in the questions, students apply the formulas and equations they remember and upon failing to solve the problem, they just proceed to the next formula and equation that they can remember without even thinking about the cause of the failure [1]. According to another study, the students in introductory physics courses stated that they understand the topics in the class but fail when it comes to solving problems [5]. This is one of the issues, for which scientists should inquire about the underlying reasons. Many studies refer to the concept of force, and it is possible to categories these studies into four types [6]: (i) students' understanding of the concept of force, (ii) students' level of understanding the concept of force, (iii) alternative approaches to teaching and learning, and (iv) studies focusing on teaching specific types of force.

The efforts to understand students' alternative ideas and the difficulties in learning topics and concepts related to physics generally involve the analysis of how students think about these topics and concepts [7]. Such analyses are of course indispensable for helping teachers learn about learners, make assessments and design the course. To this effect, there are numerous studies in the literature $[8,9,10$ $11,12,13,14,15]$. However, evaluating how students think about physics only by the success or number of correct answers in comprehension tests falls short in obtaining detailed information about the learner (Kim and Pak, 2002). Researchers also gravitate towards qualitative studies to get more detailed information. For instance, [16] used phenomenological research pattern, which is a qualitative research pattern, to qualitatively determine physics and science teacher candidates' misconceptions about 'centre of mass' and 'centre of gravity'. To this end, they applied open-ended conceptual comprehension tests and semi-structured interviews. As a result of the analysis, they identified various misconceptions such as 'centre of gravity and centre of mass are the same', 'centre of gravity is the mid-point of the object', 'mass and weight are different, thus, centre of mass and centre of gravity are also 
different' and 'centre of mass does not change but centre of gravity changes'. In this context, it is observed that their study explains the 'the number of misconceptions that they have' instead of 'what these misconceptions are'. However, it should be noted that in such research studies, data collection and analysis entail a lengthy and arduous process. This situation necessitates the use of more practical data collection and analysis methods to enable extracting thoughts out of participants' minds.

Force Concept Inventory (FCI) is a validated diagnostic test frequently used by scientists/educators who study Newtonian mechanics [17]. Diagnostic tests usually consist of multiple-choice questions with one correct answer and three or four alternatives to assess students' comprehension based only on the given choices. [18] used the FCI test in introductory physics labs for assessing the development of university students' scientific processing skills and their conceptual success in mechanical issues to compare the effects of a laboratory approach based on 7E model and validation laboratory approach. [19] used FCI to determine the misconceptions of science and technology teacher candidates related to force and motion; to eliminate these misconceptions by using research-based laboratory and confirmatory laboratory methods; to determine epistemological beliefs before and after implementation and to determine the relationship between success and misconceptions with epistemological beliefs. FCI has been used not only for laboratory approaches but also to evaluate the effectiveness of physics courses. For instance, [20] utilised FCI to investigate the impact of a physics course on freshman students' conception of fundamental Newtonian mechanics. This test is applied as an evaluation tool before or after each topic taught at every level in physics/science education not only in Turkey but also in many other countries in high schools as well as universities [21, 22, 23].

FCI is used to evaluate students' understanding and perception of physics as well as investigating the efficiency of teaching, and it provides very useful results [24]. This test was used by [24] not only to analyse the number of correct answers given but also to obtain useful information on student models that form these answers by considering all student responses and studying the relationship between various questions. Bao developed an analysis to enable quantitative evaluation of possible student models and allowed to obtain detailed information on multiple-choice questions.

The present study makes use of concentration factor, which comprises the first part of the analysis developed by [24]. Rather than being a measurement of performance generally on correct answers, which is a characteristic of multiple-choice questions, a concentration factor is a statistical approach that gives information about how student answers are distributed/ disseminated. For example, it gives information about how students who answer the same question concentrate on a particular choice or the distribution of the answers among different choices due to random decisions. Therefore, it also becomes possible to classify students modelling situations related to the concept. What is meant by modeling situation is that the analysis indicates the degree of relative importance of the models of students' responses in a given class. A study conducted by [25] shows how to analyse a multiple-choice test using all the questions and inaccurate answers via concentration analysis. For this study, the data obtained by applying FCI to 778 engineering students enrolled in 14 different classes at Maryland University are investigated. In addition, the study argued how to use concentration analysis to design and develop a research-based multiple-question test. In this sense, it was emphasised that the concentration analysis is much more comprehensive and informative than the traditional analysis methods because, besides the distribution of all answers, the analysis also gives the distribution of wrong answers. This information provides a significant clue to teachers regarding course design, course evaluation and measurement of pre- and post-course student performance. Moreover, this feature will allow examining students' previous knowledge levels which is crucial in improving their learning of scientific understanding, and it will help in determining how learners model this information in their minds. Thus, we believe that studies towards categorising FCI concepts are important for helping students learn physics and use this information in daily-life problem-solving.

\section{Aim of the Study}

The aim of this study is to obtain information about modelling situations related to the topic by performing concentration analysis of the teacher candidates' responses to Force Concept Inventory. For this purpose, the study seeks answers to the following questions:

1. Which model includes the response scores of teacher candidates to Force Concept Inventory and the concentration factor?

2. Which model includes the response scores of teacher candidates to Force Concept Inventory and the concentration deviation?

\section{Materials and Methods}

\subsection{Model of the Study}

The research was carried out according to survey model, which is a quantitative research method. This modelling approach tries to make sense of the event, individual or object under investigation as it is in its own state [26, 27]. The main goal of survey research is to describe the existing situation [28]. Thus, this type of study endeavors to answer 'What?' question. The present study was conducted in accordance with survey model as it was 
aimed at determining the teacher candidates' understanding of force.

\subsection{Participants}

The study was carried out in the Fall semester of the academic year 2015-2016 with participation from 95 teacher candidates who were first-year students in the Science Education Program at a university in the Western Black Sea region of Turkey.

\subsection{Data Collection Tool}

In this study, FCI was used to determine the science teacher candidates' understanding of force. Known as Force Concept Inventory or FCI, this test was developed by [29] to determine high-school and university students' understanding of fundamental concepts of mechanics and alternative ideas. FCI is a multiple-choice test comprising 29 questions designed to determine the understanding of high-school and university students in six main dimensions of Newtonian Physics [29]. These are:

- Kinematics,

- $(1,2,3)$ Newton's laws,

- (4) The combined effect of force (superposition),

- (5) Types of forces.

[29] Applied FCI to more than 1500 high-school and more than 500 university students and supported it with interviews to make it valid and reliable.

\subsection{Analysis of Data}

Concentration analysis was used in data analysis. This is a statistical approach devised by [25] to analyse the number of alternative concepts and the extent of concentration and significance, rather than focusing only on correct answers, using the students' answers given to multiple-question tests. In the first stage of the analysis, concentration score (S), concentration factor (C) and concentration deviation ( $\ulcorner$ ) are calculated.

In this approach, each item of the diagnostic test is represented by two parameters: concentration score (S) and concentration factor $(\mathrm{C})$. Concentration score is the ratio of correct answers given by students for each of the multiple-choice questions and it takes a value between 0 and 1 . It is calculated according to the following formula:

$$
S=n c / N
$$

(nc: number of given correct answers to an item, $\mathrm{N}$ : the total number of student answers)

Accordingly, the concentration factor is the concentration of the students' answers given to each item's different choices. The concentration factor varies between 0 and 1 . The formula for $\mathrm{C}$ is given below:

$$
C_{f}=\frac{\sqrt{m}}{\sqrt{m}-1}\left(\frac{\sqrt{\sum_{i=1}^{m} n_{i}^{2}}}{N}-\frac{1}{\sqrt{m}}\right)
$$

(m: number of options, ni: the total number of students who choose option $\mathrm{i}, \mathrm{N}$ : the total number of student answers)

[24] also enabled the calculation of concentration for incorrect answers. This is called the concentration deviation $(\ulcorner)$. The concentration deviation is a calculation that gives the concentration of students' alternative ideas. Its formula is as follows:

$$
\Gamma=\frac{\sqrt{\mathrm{m}-1}}{\sqrt{\mathrm{m}-1}-1} \times\left(\frac{\sqrt{\sum_{\mathrm{i}=1}^{\mathrm{m}} \mathrm{n}_{i}^{2}-\mathrm{S}^{2}}}{(\mathrm{~N}-\mathrm{S})}-\frac{1}{\sqrt{\mathrm{m}-1}}\right)
$$

(All the symbols are the same as in the concentration factor, and ns refers to the number of students' answers to the correct choice.)

The greatest advantage of the concentration deviation or $\ulcorner$ is that it is not affected by the scores. Therefore, we can learn more about students' wrong answers by looking at the $\mathrm{S}-\Gamma$ relationship rather than the distribution in the $\mathrm{S}-\mathrm{C}$ graph. In this context, teacher candidates' response to FCI is analysed through concentration analysis [25]. In the second stage of the analysis, students' model states were categorised in light of the values obtained in the first stage. Bao's three-level coding scheme was used to classify student responses.

Table 1. Three-level coding scheme for classification of student model states

\begin{tabular}{|c|c|c|c|c|c|}
\hline Score & Level & C & Level & $\Gamma$ & Level \\
\hline $0 \sim 0.4$ & $\mathrm{~L}$ & $0 \sim 0.2$ & $\mathrm{~L}$ & $0 \sim 0.2$ & $\mathrm{~L}$ \\
\hline $0.4 \sim 0.7$ & $\mathrm{M}$ & $0.2 \sim 0.5$ & $\mathrm{M}$ & $0.2 \sim 0.4$ & $\mathrm{M}$ \\
\hline $0.7 \sim 1.0$ & $\mathrm{H}$ & $0.5 \sim 1.0$ & $\mathrm{H}$ & $0.4 \sim 1.0$ & $\mathrm{H}$ \\
\hline
\end{tabular}

L: Low, M: Medium, H: High

Such a classification helps to encode factors that enable getting student model states for each multiple-choice question. Based on this, student model states are classified

\begin{tabular}{|c|c|c|}
\hline & Pattern & Implication \\
\hline- & $\mathbf{L L}$ & $\begin{array}{l}\text { Student responses are usually like random } \\
\text { guesses. }\end{array}$ \\
\hline \multirow[b]{2}{*}{$N$} & LH & $\begin{array}{l}\text { Most of the responses concentrate on the same } \\
\text { distracter. (One dominant incorrect model) }\end{array}$ \\
\hline & HH & $\begin{array}{l}\text { Students display satisfactory results related to the } \\
\text { concept (One correct model) }\end{array}$ \\
\hline \multirow{4}{*}{$m$} & $\mathbf{L M}$ & $\begin{array}{l}\text { Responses concentrate on two choices but both } \\
\text { are wrong. (Two possible incorrect models) }\end{array}$ \\
\hline & MH & $\begin{array}{l}\text { One possible dominant model (Two unpopular } \\
\text { models) }\end{array}$ \\
\hline & MM & $\begin{array}{l}\text { Responses concentrate on two choices. One of } \\
\text { them is correct. (Two popular models) }\end{array}$ \\
\hline & ML & Two unpopular models \\
\hline
\end{tabular}
as follows:

Table 2. Possible model classifications of students 
In Table 2, the first category corresponds to the null model, the second category corresponds to situations where there is only one model, and the third category denotes two models. Moreover, with the knowledge obtained about concentration factor and scores within the scope of study, the answers and their classification are shown here in the 2D graph. This plot has been generated taking into consideration the $\mathrm{S}-\mathrm{C}$ boundary lines stated by [24] (see Figure 1).

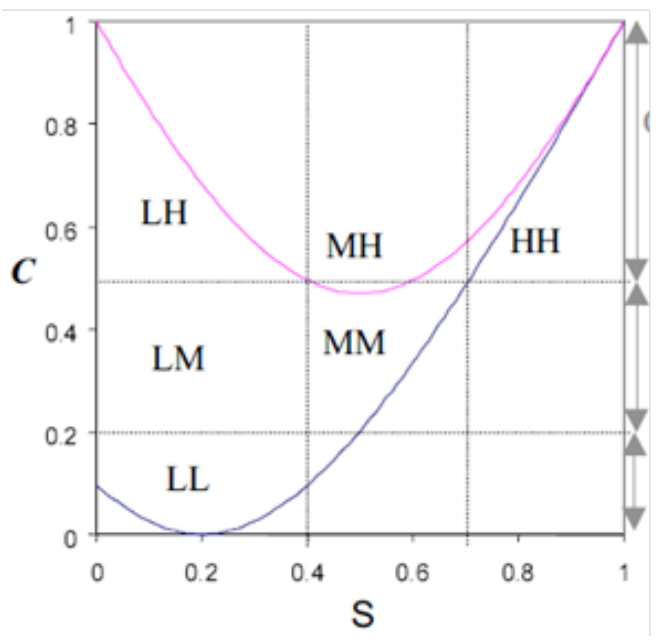

Figure 1. S-C graph

The classification and the plot obtained from the analysis of FCI data are presented in the following section.

\section{Results}

The concentration analysis results of teacher candidates' responses to FCI implementation are shown in Table 3 in terms of concentration factor and score. Furthermore, the concentration deviation is also shown to indicate the concentration of teacher candidates' alternative concepts.

Table 3 displays the encoding list for all 29 problems in the FCI. When S-C classification from the table is examined, it is understood that student responses can be classified into three categories. MM modelling, which indicates success for students, can be seen in only one question (Question 19), and it is observed that LL and LM types are more common. Prevalence of LL shows a tendency towards the common incorrect model.

When $\mathrm{S}-\ulcorner$ classification is examined, it is noted that high $\ulcorner$ questions have significantly low scores. Since high $\ulcorner$ represents strong distracters, it is observed that teacher candidates displayed a tendency to choose the same distracters. This is an indication of common incorrect student models.
Table 3. Relevant model states containing the scores, concentration factor and concentration deviation of the responses of teacher candidates

\begin{tabular}{|c|c|c|c|c|c|}
\hline Question & $\mathbf{S}$ & C & $\Gamma$ & $\begin{array}{l}\text { Model } \\
\text { (S\&C) }\end{array}$ & $\begin{array}{l}\text { Model } \\
(\text { S\& })\end{array}$ \\
\hline 1 & 0.16 & 0.17 & 0.22 & LL & LM \\
\hline 2 & 0.13 & 0.47 & 0.59 & LM & $\mathrm{LH}$ \\
\hline 3 & 0.11 & 0.21 & 0.24 & LM & LM \\
\hline 4 & 0.06 & 0.09 & 0.06 & LL & LL \\
\hline 5 & 0.09 & 0.17 & 0.17 & LL & LL \\
\hline 6 & 0.35 & 0.11 & 0.13 & LL & LL \\
\hline 7 & 0.24 & 0.11 & 0.18 & LL & LL \\
\hline 8 & 0.09 & 0.46 & 0.54 & LM & $\mathrm{LH}$ \\
\hline 9 & 0.17 & 0.20 & 0.28 & LL & LM \\
\hline 10 & 0.28 & 0.16 & 0.26 & LL & LM \\
\hline 11 & 0.22 & 0.21 & 0.33 & LM & LM \\
\hline 12 & 0.36 & 0.07 & 0.04 & LL & LM \\
\hline 13 & 0.07 & 0.16 & 0.15 & LL & LL \\
\hline 14 & 0.16 & 0.05 & 0.06 & LL & LL \\
\hline 15 & 0.27 & 0.17 & 0.29 & LL & LM \\
\hline 16 & 0.35 & 0.40 & 0.74 & LM & $\mathrm{LH}$ \\
\hline 17 & 0.22 & 0.05 & 0.09 & LM & LL \\
\hline 18 & 0.11 & 0.13 & 0.14 & LL & LL \\
\hline 19 & 0.47 & 0.35 & 0.63 & MM & MH \\
\hline 20 & 0.18 & 0.15 & 0.21 & LL & LM \\
\hline 21 & 0.15 & 0.05 & 0.06 & LL & LL \\
\hline 22 & 0.11 & 0.38 & 0.47 & LL & $\mathrm{LH}$ \\
\hline 23 & 0.21 & 0.14 & 0.22 & LM & LM \\
\hline 24 & 0.09 & 0.14 & 0.17 & LL & LL \\
\hline 25 & 0.21 & 0.11 & 0.17 & LM & LL \\
\hline 26 & 0.14 & 0.06 & 0.07 & LL & LL \\
\hline 27 & 0.32 & 0.08 & 0.10 & LM & LL \\
\hline 28 & 0.21 & 0.07 & 0.11 & LM & LL \\
\hline 29 & 0.22 & 0.21 & 0.33 & LM & LM \\
\hline
\end{tabular}

The table below shows the questions covered under the S-C classification.

Table 4. Conceptual questions in model states (S\&C)

\begin{tabular}{|c|c|c|}
\hline $\begin{array}{c}\text { Model } \\
\text { (S\&C) }\end{array}$ & Question No & \% \\
\hline LL & $\begin{array}{c}1,4,5,6,7,9,10,12,13,14,15,18,20,21, \\
22,24,26\end{array}$ & 58.6 \\
\hline LH & - & 0 \\
\hline HH & - & 0 \\
\hline LM & $2,3,8,11,16,17,23,25,27,28,29$ & 37.9 \\
\hline MH & - & 0 \\
\hline MM & 19 & 3.5 \\
\hline ML & - & 0 \\
\hline
\end{tabular}


According to Table 4, almost 59\% of FCI student response models were null models, (LL), or in other words, close to random guessing. Almost $38 \%$ of responses indicated a combination of medium concentration and low score (LM) modelling whereas the ratio of medium concentration with the lower score was found to be $3.5 \%$ (MM). Only the 19th question displays a medium level of modelling (force-motion relationship). It is observed that almost half of the teacher candidates $(n=45)$ chose the correct answer to this question. A graphical representation of $\mathrm{S}-\mathrm{C}$ graph is given below.

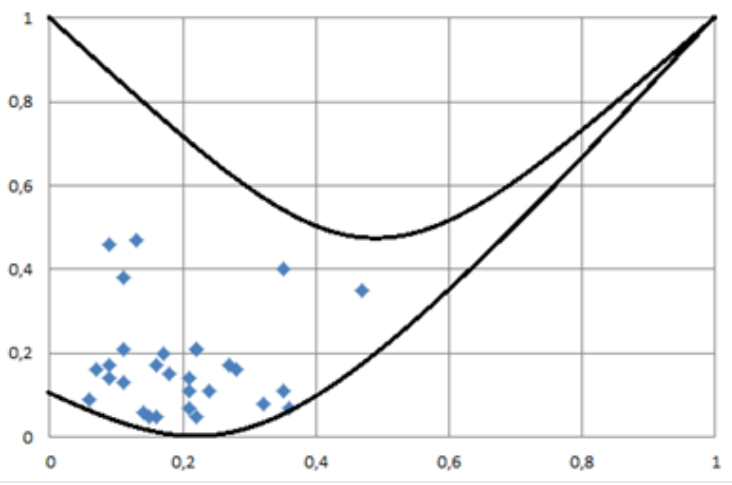

Figure 2. S-C plot for 29 questions of FCI

Table 4 shows the questions covered under the $\mathrm{S}_{-}-$ classification.

According to Table 5, 48.3\% of teacher candidates were in null models (LL) which means low scores and low concentration. Only $41.4 \%$ of teacher candidates were in medium modelling states (LM, MH and ML). Furthermore, although there was no teacher candidate in $\mathrm{HH}$ level in which there was only one modelling state, instances of LH modelling in which there was a dominant incorrect model exist (Questions 2,8 and 22).

Table 5. Conceptual questions in model states (S\& ᄃ)

\begin{tabular}{|c|c|c|}
\hline $\begin{array}{c}\text { Model } \\
(\mathbf{S \&} \boldsymbol{)})\end{array}$ & Question No \\
\hline LL & $\begin{array}{c}4,5,6,7,13,14,17,18,21,24,25,26,27, \\
28\end{array}$ & 48.3 \\
\hline LH & $2,8,22$ & 10.3 \\
\hline HH & - & 0 \\
\hline LM & $1,3,9,10,11,15,20,23,29$ & 31 \\
\hline MH & - & 6.9 \\
\hline MM & 12 & 0 \\
\hline ML & & 3.5 \\
\hline
\end{tabular}

\section{Conclusions, Discussion and Suggestions}

In this study, a concentration analysis was performed to analyse teacher candidates' answers to FCI and to obtain a pattern of their alternative concepts and present conceptual knowledge [24, 25]. Concentration scores and concentration factors obtained from teacher candidates' answers during the analysis were combined for a three-level encoding and categorisation of responses. In light of the findings, it can be said that the answers provided by teacher candidates are generally in the null model state; in other words, they are consequences of random responses. Moreover, a look at the FCI data (see Table 3) shows that average concentration score of teacher candidates is 0.198, and according to [25] this score corresponds to a low level (see Table 1). In this context, it can be argued that teacher candidates' modelling related to the concept of force is generally based on alternative concepts. However, students' concept-related modelling on the graphic was expected to in be $\mathrm{HH}$ state and near the conjunction of red and blue lines where concentration and scores are high $(\mathrm{S}=0.7 \sim 1.0 ; \mathrm{C}=0 \sim 1.0)$. That is because this area proves that students displayed good results related to the specified concept and they have been successful. [20] study evaluated students' FCI pre-test and post-test data and the mean scores of correct answers with the standard deviation and concluded that their conceptual understanding of force and motion at the beginning of their university education was extremely weak and full of misconceptions. These and similar studies show that even though the information obtained through correct answers of students is useful, it falls short in examining the distribution and change of their alternative ideas. The present study investigated student responses to a test; the data obtained from wrong answers show that the teacher candidates answered the majority of the questions based on random guessing and were sometimes unable to choose between two or more options and, consequently, were found to be in a mixed modelling state. The studies conducted by [25] also examined responses to FCI in the traditional and tutorial classes after pre-test and post-test implementations, and it is stated that in the pre-test, very few of the FCE questions were near the high-probability zone and most questions corresponded to LH and LM states. In the post-test, it is observed that the student modelling is generally in MM state, meaning a considerable number of students insisted on a wrong model. In the tutorial classes, high scores and high concentration were seen in the post-tests and student responses were generally in the $\mathrm{HH}$ region. An examination of concentration deviations of pre-tests and post-test of both groups displayed a wide distribution, and it was concluded that the wrong answers given by students were similar in pre-tests and post-tests. It is seen that the obtained data are very important when the [25] study and the present study are taken into consideration. These studies show how to carry out a concentration analysis using all the questions and the wrong answers to analyze a multiple-choice test. Similar situations are emphasized in the studies on different concepts with this analysis method [30, 31, 32, 33]. As these studies show the current situation and the 
change over time, it may be useful to employ them among participants from various levels and with distinct characteristics and to discuss the results on common grounds to design new/different learning environments. In addition, the same students' mental models related to the same concept in certain time periods can be determined and the change in modelling can be described.

In accordance with the obtained results and emphasized points, it can be said that this analysis method is suitable for developing more effective multiple-choice tests and comprehensively assessing the learning situation of a class. In this context, this analysis can be used by researchers to develop measurement tools dealing with different concepts and by educators to easily analyze the learners' model states at the beginning and/or end of instruction instead of time consuming qualitative analyses via multiple-choice questions.

\section{REFERENCES}

[1] D P Maloney, Research on Problem Solving. New York: Macmillan, 1994.

[2] E Mazur, Peer instruction: A users' manual. upper saddle river, NJ: Prentice Hall, 1996.

[3] E Kim, S J Pak, Students do not Overcome Conceptual Difficulties After Solving 1000 Traditional Problems. American Association of Physics Teachers, Vol. 70 (7), pp. 759-765, 2002.

[4] M A Kurnaz, Enerji kavramının üniversite 1. sınıf seviyesinde öğrenim durumlarının analizi [Analysis of the learning situations of the concept of energy at the freshman level]. Trabzon: KTU, 2007.

[5] M Özel, Başarılı Bir Fizik Eğitimi Için Stratejiler [Strategies for a successful physics education], Pamukkale University Journal of Education, Vol.16, pp.79-88, 2005.

[6] M A Kurnaz, C Eksi, An Analysis of High School Students' Mental Models of Solid Friction in Physics. Educational Sciences: Theory \& Practice, Vol.15(3), pp.787-795, 2015.

[7] M Uzunkavak, Fizik Eğitiminde Başarıyı Etkileyen Kavrama Yanlışlıklarının Giderilmesinin Araştırılması [Investigation of Elimination of Misconceptions Influencing Success in Physics Education]. Isparta: Süleyman Demirel University, 1988.

[8] Ö Anıl, H Küçüközer, Ortaöğretim 9. Sınıf Öğrencilerinin Düzlem Ayna Konusunda Sahip Oldukları Ön Bilgi Ve Kavram Yanılgılarının Belirlenmesi [Determining the $9^{\text {th }}$ Year Secondary Education Students' Prior Knowledge and Misconceptions About Plane Mirror]. Journal of Turkish Science Education, Vol.7(3), pp.104-122, 2010.

[9] S Aydoğan, B Güneş, Ç Gülçiçek, Isı ve Sıcaklık Konusundaki Kavram Yanılgıları [The Misconceptions about Heat and Temperature]. Gazi University Journal of Gazi Education Faculty, Vol.23(2), pp.111-124, 2003.

[10] N F Azman, M Ali, L F Mohtar, The Level of
Misconceptions on Force and Motion among Physics Pre-Services Teachers in UPSI. 2nd International Seminar on Quality and Affordable Education, pp.128-132, 2013.

[11] D E Trowbridge, L C McDermott, Investigation of Student Understanding of Concept of Velocity in One Dimension. American Journal of Physics, Vol.48, pp.1020-1028, 1980.

[12] D E Trowbridge, L C McDermott, Investigation of Students Understanding of the Concept of Acceleration in One Dimension. American Journal of Physics, Vol. 49, pp.242-253, 1981.

[13] D Palmer, Students' Alternative Conceptions and Scientifically Acceptable Conceptions about Gravity. International Journal of Science Education, Vol. 23, pp.691-706, 2001.

[14] S Eryılmaz Toksoy, A R Akdeniz, Öğrencilerin Kuvvet ve Hareket Ünitesi ile İlgili Problemleri Çözerken Güçlük Çektikleri Noktaların İpucu Kartlarıyla Belirlenmesi [Determining Student Difficulties in Solving Problems Related to Force and Motion Units via Hint Cards]. Education and Science, Vol 40(180), 343-362, 2015.

[15] T Martin-Blas, L Seidel, A Serrano-Fernandeza, Enhancing Force Concept Inventory Diagnostics to Identify Dominant Misconceptions in First-Year Engineering Physics. European Journal of Engineering Education, Vol.35(6), pp.597-606, 2010.

[16] V N Kirtak Ad, M S Kocakülah, Fizik ve Fen Bilgisi Öğretmen Adaylari Farki Fark Edebiliyor mu? Kütle ve Ağırlık Merkezi Kavramları Örneği [Can pre-service physics and science teachers detect the difference? An example of centre of mass and centre of gravity concepts]. Journal of Turkish Science Education, Vol.10(4), pp.56-74, 2013.

[17] C Henderson, Common Concerns about the Force Concept Inventory. Physics Teacher, Vol.40, pp.542-547, 2002.

[18] U Kanlı, 7E Modeli Merkezli Laboratuvar İle Doğrulama Laboratuvar Yaklaşımlarının Öğrencilerin Bilimsel Süreç Becerilerinin Gelişimine ve Kavramsal Başarılarına Etkisinin Karşılaştırılması. [The effects of a laboratory based on the 7e model with verification laboratory approach on students' development of science process skills and conceptual achievement.] Ankara: Gazi University, 2007.

[19] V Göksu, Sorgulayıcı araştırmaya dayalı laboratuar ile doğrulayıc1 laboratuar yöntemlerinin fen ve teknoloji ögretmen adaylarının başarı, kavram yanılgısı ve epistemolojik inançları üzerine etkisi. [The effects of inquiry based and verification laboratory instruction on preservice science teachers' achievement, misconceptions about force and motion and their epistemological beliefs.] Ankara: Gazi University, 2011.

[20] O Kahveci, K Kantarl1, Fizik I Dersinin Birinci Yil Lisans Öğrencilerinin Newton Mekaniğindeki Kavramsal Anlayışı Üzerine Etkisi [The Effect of Introductory Physics Course on the Conceptual Understanding of Newtonian Mechanics of the First Year Undergraduate Students]. Anadolu University Journal of Science and Technology, Vol.9(1), pp.41-50, 2008.

[21] P Gustafsson, Improved Method in Distance Teaching of Physics. European Journal of Physics, Vol.25(2), pp.185-191, 2004. 
[22] R R Hake, Interactive-engagement vs Traditional Methods: A Six-thousand-student Survey of Mechanics Test Data for Introductory Physics Courses. American Journal of Physics, Vol.66, pp.64-74, 1997.

[23] A Savinainen, P Scott, Using the Force Concept Inventory to monitor student learning and to plan teaching. Physical Education, Vol.37(1), pp.53-58, 2002.

[24] L Bao, Dynamics of Student Modeling: A Theory, Algorithms, and Application To Quantum Mechanics. PhD Dissertation, University of Maryland, Maryland, 1999.

[25] L Bao, E F Redish, Concentration Analysis: A Quantitative Assessment of Student States. American Journal of Physics, Vol.69(7), pp.45-53, 2011.

[26] N Karasar, Bilimsel Araştırma Yöntemi [Scientific research methodology]. Ankara: Nobel Yayın Dağıtım, 2002.

[27] J H McMillan, S Schumacher, Research in Education: Evidence-Based Inquiry (6th ed.). Pearson Education, 2014.

[28] S Çepni, Araştırma ve Proje Çalışmalarına Giriş [Introduction to research and project studies]. Trabzon: Celepler Publishing, 2012.

[29] D Hesteness, M Wells, G Swackhamer, Force Concept Inventory. The Physics Teacher, Vol.30, pp.141-158, 1992.

[30] B G Dega, Conceptual change through cognitive perturbation using simulations in electricity and magnetism: a case study in ambo university, ethiopia. Unpublished Doctoral Thesis, University of South Africa, 2012.

[31] B G Dega, N Govender, N, Assessment of students' scientific and alternative conceptions of energy and momentum using concentration analysis. African Journal of Research in Mathematics, Science and Technology Education, Vol.20, pp.201-213, 2016.

[32] K H Philippi, An examination of student understanding of the use of models in science and conceptual understanding of electricity and magnetism. University of New Orleans Theses and Dissertations. 1114, 2010.

[33] P Vadnere, P Joshi, On analysis of the perceptions of standard 12 students regarding a physics concept using techniques of quantum mechanics. Physics Education Journal, Vol 26(4), pp. 279-290, 2009. 